\title{
Obesity and increased burden of hip and knee joint disease in Australia: Results from a national survey
}

llana N Ackerman ${ }^{1 *}$ and Richard H Osborne ${ }^{2}$

\begin{abstract}
Background: Research involving more representative samples is needed to extend our understanding of the broader impact of obesity in hip or knee joint disease (arthritis and $\mathrm{OA}$ ) beyond clinical settings. Although population-based research has been conducted in the United States, how these findings translate to other countries is unclear. Using a national approach, this study explored associations between obesity and the burden of hip and knee joint disease in Australia (in terms of prevalence, pain, stiffness, function, Health-Related Quality of Life (HRQoL) and disease severity).
\end{abstract}

Methods: A random sample of 5000 Australians ( $\geq 39$ years) from the federal electoral roll was invited to complete a mailed questionnaire to identify doctor-diagnosed hip arthritis, hip OA, knee arthritis and knee OA and evaluate the burden of these conditions. Validated questionnaires included the WOMAC Index, Assessment of Quality of Life instrument and Multi-Attribute Prioritisation Tool. Body Mass Index (BMI) was classified into underweight/normal weight $\left(\leq 24.99 \mathrm{~kg} / \mathrm{m}^{2}\right)$, overweight (25-29.99) or obese ( $\left.\geq 30\right)$. Multiple logistic regression was used to estimate odds of arthritis and OA, with demographic and socioeconomic variables included in the models. Associations between BMI and other variables were investigated using analysis of covariance, with adjustment for age and sex.

Results: Data were available from 1,157 participants (23\%). Overweight participants had increased odds of knee arthritis (adjusted OR (AOR) 1.87, 95\%Cl 1.14-3.07) and knee OA (AOR 2.11,95\%Cl 1.07-4.15). Obesity was associated with higher prevalence of hip arthritis (AOR 2.18,95\%Cl 1.17-4.06), knee arthritis (AOR 5.47, 95\%Cl 3.35-8.95) and knee OA (AOR 7.35, 95\% Cl 3.85-14.02). Of those with arthritis or OA, obese individuals reported more pain (for hip arthritis, hip OA and knee OA), greater stiffness (for hip arthritis, knee arthritis and knee OA), worse function (all diagnoses), lower HRQoL (for hip arthritis and hip OA) and greater disease severity (all diagnoses).

Conclusions: This national study has demonstrated that the odds of arthritis and OA was up to 7 times higher for obese individuals, compared with those classified as underweight/normal weight. Concurrent obesity and joint disease had a marked impact on several key aspects of wellbeing, highlighting the need for public health interventions.

Keywords: Obesity, Osteoarthritis, Quality of Life, Health status

\footnotetext{
* Correspondence: i.ackerman@unimelb.edu.au

${ }^{1}$ Melbourne EpiCentre, Department of Medicine (Royal Melbourne Hospital),

The University of Melbourne, Melbourne, Australia

Full list of author information is available at the end of the article
} 


\section{Background}

Hip and knee joint disease (arthritis and osteoarthritis $(\mathrm{OA})$ ) are ongoing public health challenges internationally, which are set to worsen with ageing populations. The number of hip and knee replacements in Australia has almost doubled in the past decade and over 80,000 procedures are now undertaken annually, predominantly for OA [1]. In recent years, the prevalence of obesity has also risen substantially in many countries including Australia, Canada and the United States (US) [2], with $61 \%$ of Australian adults considered to be overweight or obese [3]. Overweight and obesity represent the third highest risk factors for the burden of illness in Australia, after smoking and hypertension [3].

Obesity is thought to contribute to the development and progression of OA through increased mechanical load and more recently, via hormonal and metabolic mechanisms $[4,5]$. There is some evidence to support a relationship between obesity and risk of hip OA [6], and several large studies have shown a clear link between obesity and risk of knee OA [7-12]. To date, the association between obesity and burden of hip and knee joint disease (in terms of prevalence and impact) has not been explored in Australia. Specific data pertaining to the hip and knee joints are not available from Australian population-based studies, including the triennial National Health Survey and state-based health surveys, which have collected data on self-reported arthritis and OA affecting any joint/s [13-16]. Nonetheless, two studies from single Australian states have identified a relationship between increasing Body Mass Index (BMI) and risk of non-specific arthritis. Analysis of data from the Victorian Population Health Survey showed that overweight individuals were $60 \%$ more likely to have arthritis and those who were obese had twice the risk [13]. A similar relationship between obesity and risk of general arthritis was also evident from the South Australian Health Omnibus Survey [14].

Information on obesity as both a risk factor and a determinant of quality of life is important for understanding how to deal with hip and knee joint disease at a population level. However, many studies investigating the relationship between obesity and the impact of hip and knee OA have been conducted in clinical settings, with limited generalisability. Overweight and obesity have been associated with impaired quality of life in a primary care study of patients with hip or knee OA [17] and most recently, computer simulation models demonstrated a substantial expected loss of quality-adjusted life years for obese individuals with knee OA [18]. Australian research involving obese adults recruited from gastric banding and weight loss programs found that a knee OA subgroup had poorer physical functioning, increased bodily pain and lower Health-Related Quality of Life (HRQoL), compared to those without OA [19]. Clinical studies and those involving convenience samples have also found obesity to be associated with increased pain [20-22], worse health status [22] and greater disability in hip or knee OA [22-24], although the applicability of these findings to other settings is not clear.

Research using more representative samples is needed to extend our understanding of the personal impact of concurrent obesity and hip or knee joint disease beyond primary care and outpatient settings. The use of population-based sampling enables recruitment of people with a range of disease severity, including those with less severe joint disease who may not be receiving treatment and are therefore unlikely to be included in clinical studies. This is important for ensuring that research findings are relevant across the disease severity spectrum, and not limited to only those with more severe joint disease. Additionally, population-based sampling facilitates the recruitment of people from varied socioeconomic backgrounds, representing an advance over clinical studies which commonly comprise patients from a limited catchment area. To date, our understanding of the relationship between obesity and personal impact of arthritis or OA comes predominantly from population-based research conducted in the US [25-29]. Most studies in this area have focused on functional status, disability and activity limitations, although other population-based studies (for example, those investigating racial differences in pain among people with knee OA $[30,31]$ ) have included Body Mass Index (BMI) as part of a range of covariates. Whether the impact of obesity is similar in other countries is not known and further investigation of the relationships between obesity and pain, function and HRQoL in hip and knee joint disease in other populations is warranted.

Using a national approach, this study aimed to:

1. investigate associations between obesity and the prevalence of hip and knee joint disease (arthritis and $\mathrm{OA}$ ) in Australia; and

2. explore associations between obesity and pain, stiffness, physical function, HRQoL and disease severity among people with hip or knee joint disease.

\section{Methods}

\section{Study design}

This paper reports the results of a national crosssectional survey.

\section{Participants}

As electoral enrolment and voting is compulsory for Australians aged 18 years and over, the federal electoral roll provides comprehensive coverage of the Australian adult population. Medical researchers can apply for an electoral roll extract for use in research or public health screening programs. In May 2009, following approval by 
The University of Melbourne Human Research Ethics Committee and the Australian Electoral Commission, we obtained an extract which included the names, age group, sex and postal address details for a random sample of 10,000 individuals drawn from all federal electoral divisions. This extract was used to randomly select a sample of the Australian population aged 39 years and over from all states and territories $(\mathrm{N}=5,000)$, stratified by age range category. The lowest two age categories (39-43 years and 44-48 years) were over-sampled to increase precision, as the prevalence of arthritis is lower among younger people [13,32].

\section{Procedure}

In June 2009, an introductory letter, plain language statement and questionnaire were mailed to the selected sample (Figure 1). Reply-paid envelopes were provided to maximize response rates. To minimise participant burden and maximise response rates, return of a completed questionnaire was deemed to constitute consent. This procedure was approved by The University of Melbourne Human Research Ethics Committee. Limited follow-up with repeat administration of the study questionnaire was undertaken for a random sample of non-participants approximately 6 weeks after the initial mailing (stratified by state/territory, $n=300$ ). All questionnaires marked 'return to sender' were re-sent where an alternative postal address could be located.

Although hip OA and knee OA were the primary conditions of interest, previous studies have indicated that individual knowledge of arthritis type can be limited [16,33]. The questionnaire was therefore designed to screen for the presence of doctor-diagnosed hip OA and knee OA and doctor-diagnosed hip arthritis and knee arthritis to capture the majority of possible OA cases. Screening was performed using self-reported measures, similar to the methodology used by the US Centers for Disease Control [33]. Participants were asked:

- "have you ever been told by a doctor or other health professional that you have hip arthritis?";

- "have you ever been told by a doctor or other health professional that you have hip osteoarthritis?";

- "have you ever been told by a doctor or other health professional that you have knee arthritis?"; and

- "have you ever been told by a doctor or other health professional that you have knee osteoarthritis?"

Individuals who reported having $\mathrm{x}$-rays that showed hip or knee arthritis or OA but did not report a doctor's diagnosis for these conditions were excluded from the analyses $(n=7,<1 \%$ for hip arthritis or hip OA; $n=5,<1 \%$ for knee arthritis or knee OA).

\section{Instruments}

Three validated instruments were included in the study questionnaire. The Western Ontario and McMaster Universities Osteoarthritis (WOMAC) Index is a diseasespecific measure of health status widely used in OA research [34], with demonstrated validity, reliability and responsiveness [35,36]. It produces pain, stiffness and physical function subscale scores commonly transformed to 0 (best health) to 100 (worst health) scales. Among participants with hip or knee arthritis or OA, the total WOMAC score was used to classify joint disease severity, as reported previously [37]. A WOMAC score $<7$ was considered to be asymptomatic joint disease, 7-38 was considered to be mild-moderate disease and $\geq 39$ was considered to be severe joint disease. The Assessment of Quality of Life (AQoL) instrument is an Australian generic measure of HRQoL which was developed using the World Health Organization's (WHO) definition of health and classification of impairments, disabilities and handicaps $[38,39]$. The four dimensions covered by this instrument include Independent Living, Social Relationships, Physical Senses and Psychological Wellbeing. The AQoL instrument has demonstrated good internal consistency, and face, content and construct validity [40]. It has been used in arthritis research $[40,41]$ and Australian normative data are available [39]. The AQoL instrument produces a utility score ranging from -0.04 (worst HRQoL) to 1.00 (full HRQoL). The Hip and Knee Multi-Attribute Prioritisation Tool (MAPT) is a measure of OA disease severity and need for joint replacement surgery. The MAPT is used in all public hospitals in the state of Victoria to specifically facilitate prioritisation and care pathway triage for people with OA who may need hip or knee joint replacement. Although it has been shown to correlate with the WOMAC Index [42], the MAPT captures additional information relevant to hip and knee OA. Developed through intensive stakeholder consultation, it covers a range of constructs important to both patients and orthopaedic surgeons including pain, self-care activities, mental health, overall worsening and the ability to manage financially, care for others and maintain relationships. The MAPT has demonstrated construct validity and test-retest reliability in a large validation study [42] and produces a score ranging from 0 (least disease severity) to 100 (greatest severity).

Other self-reported data included country of birth, marital status, highest level of education, height, weight, paid and unpaid employment and premature exit from the workforce. BMI was calculated using self-reported height and weight and classified into underweight/normal weight (BMI $\leq 24.99 \mathrm{~kg} / \mathrm{m}^{2}$ ), overweight (BMI 25-29.99) and obese categories (BMI $\geq 30$ ), according to World Health Organization definitions [43]. Residential location was classified as metropolitan or provincial/rural based on 


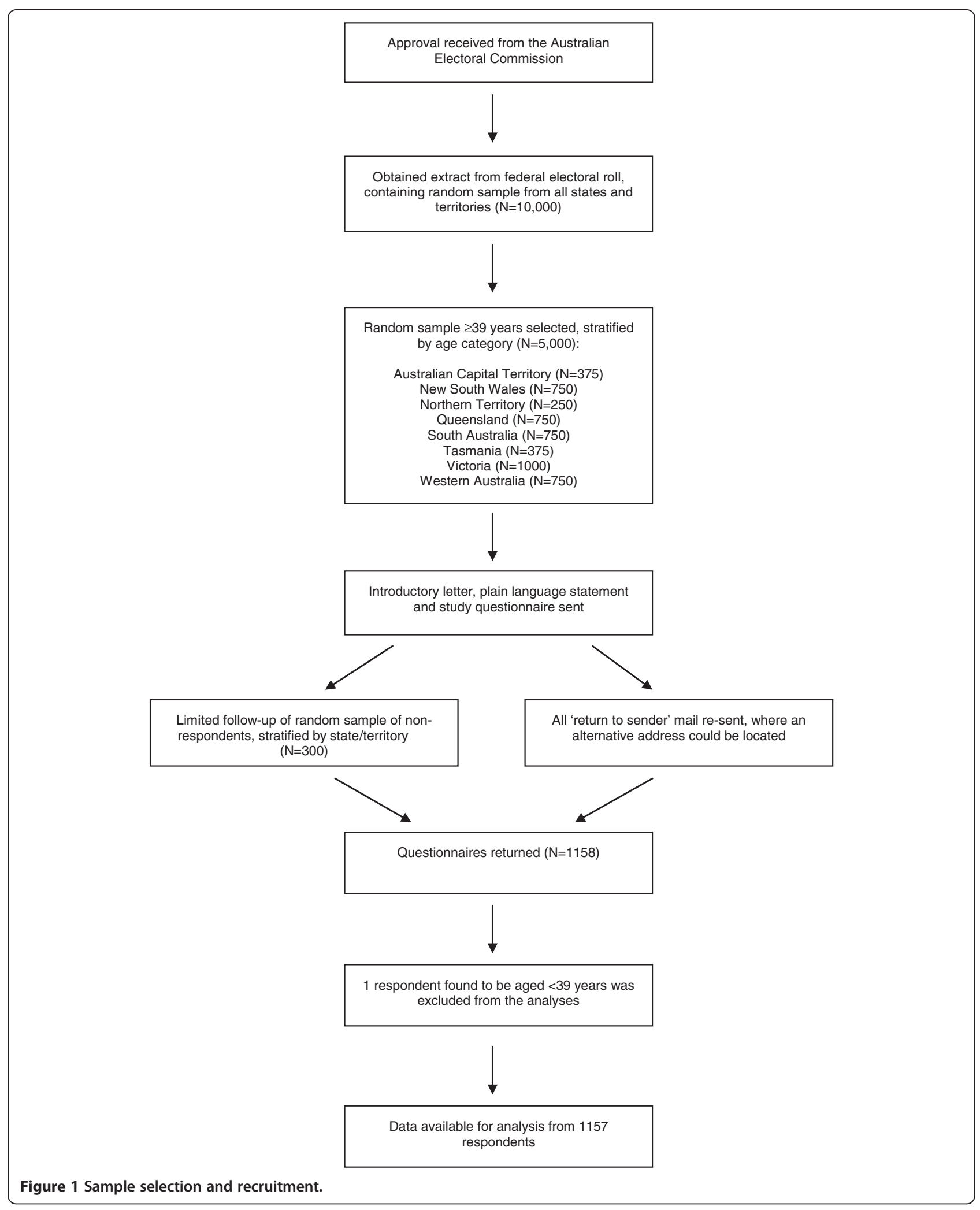


AEC ratings for each federal electoral division [44]. Socioeconomic status was approximated using postcodes to link to the Australian Socio-Economic Indexes for Areas (SEIFA) 2006 Index of Relative Socio-Economic Advantage and Disadvantage [45]. The first SEIFA decile represents geographical areas with the greatest socioeconomic disadvantage while the tenth decile represents areas with the greatest advantage.

\section{Statistical analysis}

Analyses were undertaken using SPSS 18.0 and Stata 10.1. Only limited demographic information (sex, age group, socioeconomic status and location) was available for nonparticipants; chi-square tests were used to evaluate differences between participants and non-participants.

Based on affirmative responses to the screening questions, the overall prevalence of hip or knee arthritis or OA and Clopper-Pearson confidence interval estimates were calculated. Prevalence was also calculated according to sex, age, BMI, education, marital status, country of birth, location and socioeconomic status (Additional file 1). Multiple binary logistic regression was used to generate adjusted odds ratios for the odds of hip and knee arthritis and OA, with demographic and socioeconomic variables entered simultaneously as predictors. Reference categories included male sex, age $<50$ years, BMI $\leq 24.99 \mathrm{~kg} / \mathrm{m}^{2}$ (underweight/ normal weight), primary school or less level of education, married/living with partner, born in Australia, residing in a metropolitan location and first SEIFA decile (greatest socioeconomic disadvantage) (Additional file 1).

For participants who reported hip or knee arthritis or OA, analysis of covariance (ANCOVA) was used to evaluate associations between BMI category and pain, stiffness, physical function and HRQoL (with adjustment for age and sex). Post-hoc tests used a Bonferroni adjustment for multiple comparisons. Kruskal-Wallis tests were used to evaluate the relationship between BMI category and disease severity as the distribution of MAPT scores was severely skewed and this was not improved by $\log$ transformation.

\section{Results}

\section{Participants}

Questionnaires were returned by 1,158 individuals (23\% response rate). Limited information was available for non-participants: questionnaires were returned for 91 individuals (2\%) due to incorrect address details, 45 individuals (1\%) declined to participate and 1 had died. One respondent was found to be aged less than 39 years (having been incorrectly listed in the 69-73 year age category in the federal electoral roll extract) and was subsequently excluded from the analyses. Age data for all analyses were calculated based on self-reported date of birth from the study questionnaire.
Response rates by state ranged from $15 \%$ to $31 \%$. The Northern Territory had the lowest response rate, as well as the highest proportion of return to sender mail; this may relate to the remoteness of many areas in the territory and the larger indigenous population.

\section{Comparison of participants and non-participants}

Although absolute differences between participants and non-participants were small, a greater proportion of participants were female ( $57 \%$ vs $52 \%$ for non-participants, chisquare $=8.3, \mathrm{p}<0.01)$ and living in areas with the highest socioeconomic advantage (17\% vs $14 \%$ for non-participants, chi-square=22.9, $\mathrm{p}=0.01$ ). A lower proportion of younger age groups was also seen among participants (14\% aged 39-43 years and $15 \%$ aged $44-48$ years vs $21 \%$ each for non-participants, chi-square $=90.5, \mathrm{p}<0.01)$. Sixty-seven per cent in both groups lived in metropolitan areas (chisquare $=0.0, \mathrm{p}=0.90)$.

\section{Demographics}

The demographic characteristics of the sample are summarized in Table 1.

\section{Overall prevalence of hip and knee arthritis and osteoarthritis}

Eighty-three participants reported having ever been told by a doctor or other health professional that they had hip arthritis (7\%, 95\%CI 6\%-9\%), and 57 reported hip OA $(5 \%, 95 \%$ CI $4 \%-6 \%)$. There was some overlap between the hip arthritis and hip OA groups; of those who had been told they had hip arthritis, 57\% $(n=47)$ also reported hip OA. Of those with hip arthritis or hip OA $(n=93), 8 \%$ were classified as asymptomatic, $45 \%$ as mild to moderate and $40 \%$ as severe; WOMAC scores were missing for the remaining $8 \%$.

One hundred and sixty-nine participants reported having been told they had knee arthritis (15\%, 95\%CI 13\%$17 \%)$ and 98 reported knee OA (8\%, 95\%CI 7\%-10\%). Of those who reported knee arthritis, 41\% $(n=69)$ also said they had been diagnosed with knee OA. Of those with knee arthritis or knee OA ( $n=198), 15 \%$ were classified as asymptomatic, $52 \%$ as mild to moderate and $27 \%$ as severe; WOMAC scores were missing for the remaining $7 \%$.

\section{Overweight and obesity and odds of hip arthritis and osteoarthritis}

After adjusting for demographic characteristics, obesity was associated with a higher prevalence of hip arthritis (Table 2). Participants who were obese were more than twice as likely to have hip arthritis (adjusted OR (AOR) $=2.18,95 \% \mathrm{CI} 1.17-4.06$ ), compared with those classified as underweight/normal weight. A higher prevalence of hip arthritis was also associated with increasing age (Table 2). Compared with the youngest age group, participants aged 
Table 1 Demographic characteristics of study participants

\begin{tabular}{|c|c|}
\hline Characteristic & $\begin{array}{l}\text { Overall sample } \\
(n=1157)^{*}\end{array}$ \\
\hline Age (years), median (IQR) & $57(48-69)$ \\
\hline Female, $n(\%)$ & $656(57)$ \\
\hline \multicolumn{2}{|l|}{ Body Mass index (BMI) $\left(\mathrm{kg} / \mathrm{m}^{2}\right), n(\%)$} \\
\hline Underweight / normal weight (BMI $\leq 24.99 \mathrm{~kg} / \mathrm{m}^{2}$ ) & $430(37)$ \\
\hline Overweight (BMl $25-29.99$ kg/m²) & $383(33)$ \\
\hline Obese (BMl $\geq 30$ kg/m²) & $248(21)$ \\
\hline Married or living with partner, $n(\%)$ & $924(80)$ \\
\hline Living in metropolitan area, $n$ (\%) & $775(67)$ \\
\hline \multicolumn{2}{|l|}{ SEIFA ${ }^{\dagger}$ decile, $n(\%)$} \\
\hline First (greatest socioeconomic disadvantage) & $56(5)$ \\
\hline Tenth (greatest socioeconomic advantage) & $200(17)$ \\
\hline \multicolumn{2}{|l|}{ Highest level of education completed, $n$ (\%) } \\
\hline Primary school or less & $54(5)$ \\
\hline Year 7-10 & $263(23)$ \\
\hline Year 11-12 & $213(18)$ \\
\hline Trade / technical education & $260(23)$ \\
\hline University & $356(31)$ \\
\hline Australian-born, $n(\%)$ & $894(77)$ \\
\hline English as main language spoken at home, $n(\%)$ & $1104(95)$ \\
\hline \multicolumn{2}{|l|}{ Paid work, $n(\%)$} \\
\hline Paid employment & $651(56)$ \\
\hline Retired & $426(37)$ \\
\hline Unemployed & $58(5)$ \\
\hline Stopped work due to hip or knee arthritis / OA & $7(<1)$ \\
\hline \multicolumn{2}{|l|}{ Unpaid work, n (\%) } \\
\hline Currently does unpaid work & $335(29)$ \\
\hline $\begin{array}{l}\text { Unable to do unpaid work due to hip or knee } \\
\text { arthritis / OA }\end{array}$ & $33(3)$ \\
\hline Does not do unpaid work for other reasons & $713(62)$ \\
\hline
\end{tabular}

*Total numbers for characteristics may not equal 1157 due to missing responses.

${ }^{+}$Australian Socio-Economic Indexes for Areas 2006 Index of Relative Socio-Economic Advantage and Disadvantage.

80 years and over had the greatest odds of having hip arthritis ( $\mathrm{AOR}=6.86,95 \% \mathrm{CI}$ 2.54-18.50), followed by those aged $70-79$ years (AOR=5.13, 95\%CI 2.29-11.49).

For hip OA, no association between obesity and prevalence was observed (Table 2). An increased prevalence of hip OA was associated with being female (AOR=3.39, 95\%CI $1.59-7.22)$ and aged $70-79$ years $(A O R=4.35,95 \%$ CI 1.79-10.56).

\section{Overweight and obesity and odds of knee arthritis and osteoarthritis}

Higher BMI was strongly associated with an increased prevalence of knee arthritis (Table 3). After adjusting for other demographic characteristics, participants who were overweight were more likely to report knee arthritis (AOR $1.87,95 \% \mathrm{CI} 1.14-3.07$ ) while those who were obese had the highest odds (AOR $=5.47,95 \% \mathrm{CI} 3.35-8.95)$. The prevalence of knee arthritis also increased substantially with age; those aged 70-79 years and 80 years or over had the greatest odds $(\mathrm{AOR}=3.16,95 \% \mathrm{CI} 1.67-5.99$ and $\mathrm{AOR}=5.26,95 \% \mathrm{CI}$ 2.44-11.35, respectively). A lower prevalence of knee arthritis was seen among participants who had completed high school (AOR $=0.25,95 \% \mathrm{CI} 0.11-0.60$ ), trade or technical qualifications (AOR $=0.28,95 \% \mathrm{CI} 0.13-0.65$ ) or university (AOR $=0.34,95 \% \mathrm{CI} 0.15-0.78$ ), compared to those who had completed primary school or less.

Similar to the knee arthritis group, overweight and obesity were clearly associated with an increased prevalence of knee OA (Table 3). Participants who were overweight had increased odds of having knee $\mathrm{OA}(\mathrm{AOR}=2.11,95 \% \mathrm{CI}$ 1.07-4.15) while the obese group had the highest odds (AOR=7.35, 95\%CI 3.85-14.02). The prevalence of knee OA was also higher in those aged $60-69$ years $(\mathrm{AOR}=2.76$, 95\%CI 1.34-5.69) and 70-79 years $(\mathrm{AOR}=2.78,95 \% \mathrm{CI}$ 1.26-6.11). Participants who were single, divorced or widowed were more likely to have knee $\mathrm{OA}(\mathrm{AOR}=2.11$, 95\%CI 1.23-3.62) while those who had completed high school were less likely to have knee OA (AOR $0.34,95 \% \mathrm{CI}$ 0.12-0.98).

\section{Impact of overweight and obesity in hip arthritis and osteoarthritis}

Table 4 shows that among participants with hip arthritis, pain increased significantly with greater BMI $(F=5.35$, $\mathrm{p}=0.01$ ). Post-hoc tests showed that participants who were obese had the highest pain (adjusted mean 44.3, 95\%CI 34.3-54.4), compared to those classified as underweight/normal weight (adjusted mean 23.1, 95\%CI 13.832.4). A similar pattern was seen for stiffness; those who were obese reported the greatest stiffness, compared to individuals in the underweight/normal weight group $(\mathrm{F}=3.66, \mathrm{p}=0.03)$. Post-hoc analyses indicated that participants in both the overweight and obese groups had worse physical function (adjusted mean 43.8, 95\%CI 32.1-55.5 and 45.5, 95\%CI 35.2-55.7, respectively), compared to those in the underweight/normal weight group (adjusted mean 23.8, 95\%CI 14.1-33.4).

Regardless of BMI category, the average HRQoL of participants with hip arthritis was well below Australian population norms (mean AQoL 0.83, 95\%CI 0.82-0.84, minimal important difference 0.06 AQoL units [39]). Further deterioration in HRQoL was evident with increasing BMI $(\mathrm{F}=4.44, \mathrm{p}=0.02)$; there was a significant difference in HRQoL between participants who were obese (adjusted mean 0.43, 95\% CI 0.31-0.55) and those classified as underweight/normal weight (adjusted mean 0.66, 95\% CI 0.55-0.77). Increasing BMI was also associated with 
Table 2 Prevalence and odds of hip arthritis and osteoarthritis according to demographic characteristics

\begin{tabular}{|c|c|c|c|c|c|c|}
\hline \multirow[b]{2}{*}{ Characteristic } & \multicolumn{3}{|c|}{ Hip arthritis } & \multicolumn{3}{|c|}{ Hip osteoarthritis } \\
\hline & $\begin{array}{c}\text { Prevalence } \\
n(\%)\end{array}$ & $\begin{array}{l}\text { Unadjusted OR } \\
(95 \% \mathrm{Cl})\end{array}$ & $\begin{array}{l}\text { Adjusted OR* } \\
(95 \% \mathrm{Cl})\end{array}$ & $\begin{array}{c}\text { Prevalence } \\
n(\%)\end{array}$ & $\begin{array}{l}\text { Unadjusted OR } \\
(95 \% \mathrm{Cl})\end{array}$ & $\begin{array}{c}\text { Adjusted OR* } \\
(95 \% \mathrm{Cl})\end{array}$ \\
\hline \multicolumn{7}{|l|}{ Sex } \\
\hline Male $(n=500)$ & $19(4)$ & 1.00 & 1.00 & $13(3)$ & 1.00 & 1.00 \\
\hline Female $(n=656)$ & $64(10)$ & $2.74(1.62-4.63)$ & $3.70(1.98-6.91)$ & $44(7)$ & $2.69(1.43-5.05)$ & 3.39 (1.59-7.22) \\
\hline \multicolumn{7}{|l|}{ Age group } \\
\hline$<50$ years $(n=363)$ & $14(4)$ & 1.00 & 1.00 & $11(3)$ & 1.00 & 1.00 \\
\hline $50-59$ years $(n=290)$ & $10(3)$ & $0.89(0.39-2.04)$ & $0.97(0.39-2.41)$ & $3(1)$ & $0.33(0.09-1.21)$ & $0.37(0.10-1.39)$ \\
\hline $60-69$ years $(n=230)$ & $17(7)$ & $1.99(0.96-4.12)$ & $2.01(0.87-4.61)$ & $15(7)$ & $2.23(1.01-4.95)$ & $1.95(0.78-4.88)$ \\
\hline $70-79$ years $(n=178)$ & $29(16)$ & $4.89(2.51-9.51)$ & $5.13(2.29-11.49)$ & $23(13)$ & $4.81(2.29-10.11)$ & $4.35(1.79-10.56)$ \\
\hline$\geq 80$ years $(n=82)$ & $13(16)$ & 4.77 (2.15-10.59) & $6.86(2.54-18.50)$ & $5(6)$ & $2.13(0.72-6.32)$ & $1.89(0.50-7.18)$ \\
\hline \multicolumn{7}{|l|}{ Body Mass Index (BMI) } \\
\hline Underweight / normal weight ( $n=430$ ) & $28(7)$ & 1.00 & 1.00 & $18(4)$ & 1.00 & 1.00 \\
\hline Overweight ( $n=383$ ) & $20(5)$ & $0.79(0.44-1.43)$ & $1.00(0.53-1.89)$ & $16(4)$ & $1.00(0.50-1.98)$ & $1.17(0.56-2.44)$ \\
\hline Obese $(n=248)$ & $26(10)$ & $1.68(0.96-2.93)$ & $2.18(1.17-4.06)$ & $16(6)$ & $1.58(0.79-3.16)$ & $1.62(0.77-3.45)$ \\
\hline \multicolumn{7}{|l|}{ Highest level of education } \\
\hline Primary school or less $(n=54)$ & $8(15)$ & 1.00 & 1.00 & $6(11)$ & 1.00 & 1.00 \\
\hline Year $7-10(n=263)$ & $31(12)$ & $0.75(0.32-1.74)$ & $1.01(0.37-2.76)$ & $19(7)$ & $0.62(0.23-1.62)$ & $0.62(0.20-1.94)$ \\
\hline Year 11-12 (n=213) & $12(6)$ & $0.34(0.13-0.87)$ & $0.53(0.17-1.64)$ & $10(5)$ & $0.39(0.13-1.12)$ & $0.49(0.14-1.73)$ \\
\hline Trade / technical $(n=260)$ & $15(6)$ & $0.34(0.14-0.86)$ & $0.74(0.25-2.18)$ & $10(4)$ & $0.31(0.11-0.90)$ & $0.64(0.19-2.17)$ \\
\hline University $(n=356)$ & $17(5)$ & $0.28(0.12-0.69)$ & $0.67(0.22-1.99)$ & $12(3)$ & $0.27(0.10-0.77)$ & $0.47(0.14-1.62)$ \\
\hline \multicolumn{7}{|l|}{ Marital status } \\
\hline Married / living with partner $(n=924)$ & $61(7)$ & 1.00 & 1.00 & $41(4)$ & 1.00 & 1.00 \\
\hline Single / divorced / widowed $(n=222)$ & $22(10)$ & $1.56(0.94-2.61)$ & $0.94(0.50-1.76)$ & $16(7)$ & $1.70(0.93-3.08)$ & $1.17(0.57-2.41)$ \\
\hline \multicolumn{7}{|l|}{ Country of birth } \\
\hline Australia $(n=894)$ & $59(7)$ & 1.00 & 1.00 & $42(5)$ & 1.00 & 1.00 \\
\hline Other $(n=255)$ & $24(9)$ & $1.47(0.89-2.41)$ & $1.73(0.98-3.07)$ & $15(6)$ & $1.27(0.69-2.33)$ & $1.25(0.62-2.49)$ \\
\hline \multicolumn{7}{|l|}{ Location } \\
\hline Metropolitan ( $n=775)$ & $56(7)$ & 1.00 & 1.00 & $40(5)$ & 1.00 & 1.00 \\
\hline Provincial or rural $(n=381)$ & $27(7)$ & $0.98(0.61-1.57)$ & $0.70(0.36-1.35)$ & $17(4)$ & $0.86(0.48-1.53)$ & $0.79(0.37-1.71)$ \\
\hline
\end{tabular}

OR: odds ratio; $95 \% \mathrm{Cl}$ : $95 \%$ confidence interval.

*Adjusted values were derived from multiple binary logistic regression models with sex, age group, BMI, highest level of education, marital status, country of birth, location and SEIFA decile entered simultaneously as predictors.

Socioeconomic status (SEIFA) data for hip arthritis and osteoarthritis are presented in the Additional file 1 (Table A1).

greater disease severity (Kruskal-Wallis chi-square=9.9, $\mathrm{p}=0.01)$. Participants who were obese had the greatest severity (median 14.1, IQR 2.3-55.7), followed by those who were overweight (median 8.1, IQR 0.0-38.6). Those classified as underweight/normal weight had the least severe disease (median 0.0, IQR 0.0-7.5).

For participants with hip OA, increased pain was also associated with greater BMI $(\mathrm{F}=4.04, \mathrm{p}=0.03)$. Those classified as obese had higher pain (adjusted mean 50.4, $95 \%$ CI 36.6-64.2), compared to participants in the underweight/normal weight group (adjusted mean 24.2, 95\%CI 11.9-36.5). There was a trend towards greater stiffness with increasing BMI but this was not significant $(\mathrm{F}=2.55$, $\mathrm{p}=0.09$ ). Obese participants also had worse physical function $(\mathrm{F}=3.68, \mathrm{p}=0.03)$, markedly lower HRQoL $(\mathrm{F}=4.48$, $\mathrm{p}=0.02$ ) and greater disease severity (Kruskal-Wallis chi square $=9.5, \mathrm{p}=0.01$ ), compared to those classified as underweight/normal weight (Table 4). Those with hip OA who were obese had extremely low HRQoL, compared to population norms (mean AQoL score 0.32, 95\% CI 0.18-0.47).

\section{Impact of overweight and obesity in knee arthritis and osteoarthritis}

In knee arthritis, greater stiffness was associated with increased $\mathrm{BMI}(\mathrm{F}=4.76, \mathrm{p}=0.01)$; participants who were 
Table 3 Prevalence and odds of knee arthritis and osteoarthritis according to demographic characteristics

\begin{tabular}{|c|c|c|c|c|c|c|}
\hline \multirow[b]{2}{*}{ Characteristic } & \multicolumn{3}{|c|}{ Knee arthritis } & \multicolumn{3}{|c|}{ Knee osteoarthritis } \\
\hline & $\begin{array}{c}\text { Prevalence } \\
n(\%)\end{array}$ & $\begin{array}{c}\text { Unadjusted OR } \\
(95 \% \mathrm{Cl})\end{array}$ & $\begin{array}{c}\text { Adjusted OR* } \\
(95 \% \mathrm{Cl})\end{array}$ & $\begin{array}{c}\text { Prevalence } \\
n(\%)\end{array}$ & $\begin{array}{c}\text { Unadjusted OR } \\
(95 \% \mathrm{Cl})\end{array}$ & $\begin{array}{l}\text { Adjusted OR* } \\
(95 \% \mathrm{Cl})\end{array}$ \\
\hline \multicolumn{7}{|l|}{ Sex } \\
\hline Male $(n=500)$ & $71(14)$ & 1.00 & 1.00 & $36(7)$ & 1.00 & 1.00 \\
\hline Female $(n=656)$ & $98(15)$ & $1.07(0.77-1.49)$ & $1.15(0.77-1.71)$ & $62(9)$ & $1.34(0.87-2.06)$ & $1.51(0.91-2.52)$ \\
\hline \multicolumn{7}{|l|}{ Age group } \\
\hline$<50$ years $(n=363)$ & $25(7)$ & 1.00 & 1.00 & $15(4)$ & 1.00 & 1.00 \\
\hline $50-59$ years $(n=290)$ & $39(13)$ & $2.10(1.24-3.55)$ & $1.95(1.09-3.48)$ & $18(6)$ & $1.55(0.77-3.13)$ & $1.36(0.64-2.88)$ \\
\hline $60-69$ years $(n=230)$ & $37(16)$ & $2.60(1.52-4.45)$ & $1.99(1.08-3.66)$ & $31(13)$ & $3.65(1.92-6.93)$ & $2.76(1.34-5.69)$ \\
\hline $70-79$ years $(n=178)$ & $45(25)$ & $4.67(2.75-7.92)$ & 3.16 (1.67-5.99) & $26(15)$ & $4.00(2.06-7.76)$ & $2.78(1.26-6.11)$ \\
\hline$\geq 80$ years $(n=82)$ & $22(27)$ & $5.03(2.66-9.50)$ & $5.26(2.44-11.35)$ & $7(9)$ & $2.29(0.90-5.81)$ & 1.99 (0.65-6.08) \\
\hline \multicolumn{7}{|l|}{ Body Mass Index (BMI) } \\
\hline Underweight / normal weight $(n=430)$ & $36(8)$ & 1.00 & 1.00 & $15(3)$ & 1.00 & 1.00 \\
\hline Overweight ( $n=383$ ) & $49(13)$ & $1.61(1.02-2.54)$ & $1.87(1.14-3.07)$ & $27(7)$ & $2.10(1.10-4.00)$ & $2.11(1.07-4.15)$ \\
\hline Obese $(n=248)$ & $68(27)$ & $4.21(2.71-6.54)$ & $5.47(3.35-8.95)$ & $49(20)$ & $6.83(3.74-12.48)$ & $7.35(3.85-14.02$ \\
\hline \multicolumn{7}{|l|}{ Highest level of education } \\
\hline Primary school or less $(n=54)$ & $19(35)$ & 1.00 & 1.00 & $10(19)$ & 1.00 & 1.00 \\
\hline Year $7-10(n=263)$ & $58(22)$ & $0.50(0.27-0.95)$ & $0.56(0.26-1.21)$ & $30(11)$ & $0.55(0.25-1.21)$ & $0.50(0.19-1.32)$ \\
\hline Year $11-12(n=213)$ & $24(11)$ & $0.22(0.11-0.45)$ & $0.25(0.11-0.60)$ & $13(6)$ & $0.28(0.11-0.67)$ & $0.34(0.12-0.98)$ \\
\hline Trade / technical $(n=260)$ & $27(10)$ & $0.20(0.10-0.40)$ & $0.28(0.13-0.65)$ & $16(6)$ & $0.28(0.12-0.65)$ & $0.36(0.13-1.01)$ \\
\hline University $(n=356)$ & $40(11)$ & $0.22(0.11-0.42)$ & $0.34(0.15-0.78)$ & $28(8)$ & $0.36(0.16-0.79)$ & $0.40(0.15-1.11)$ \\
\hline \multicolumn{7}{|l|}{ Marital status } \\
\hline Married / living with partner $(n=924)$ & $119(13)$ & 1.00 & 1.00 & $67(7)$ & 1.00 & 1.00 \\
\hline Single / divorced / widowed $(n=222)$ & $47(21)$ & $1.83(1.26-2.66)$ & $1.50(0.96-2.36)$ & $29(13)$ & $1.98(1.24-3.14)$ & $2.11(1.23-3.62)$ \\
\hline \multicolumn{7}{|l|}{ Country of birth } \\
\hline Australia $(n=894)$ & $131(15)$ & 1.00 & 1.00 & $70(8)$ & 1.00 & 1.00 \\
\hline Other $(n=255)$ & $37(15)$ & $0.98(0.66-1.46)$ & $1.16(0.74-1.82)$ & $27(11)$ & $1.39(0.87-2.23)$ & $1.62(0.95-2.78)$ \\
\hline \multicolumn{7}{|l|}{ Location } \\
\hline Metropolitan $(n=775)$ & $113(15)$ & 1.00 & 1.00 & $67(9)$ & 1.00 & 1.00 \\
\hline Provincial or rural $(n=381)$ & $56(15)$ & $1.01(0.72-1.44)$ & $0.88(0.54-1.44)$ & $31(8)$ & $0.94(0.60-1.46)$ & $1.00(0.54-1.85)$ \\
\hline
\end{tabular}

OR: odds ratio; $95 \% \mathrm{Cl}$ : $95 \%$ confidence interval.

*Adjusted values were derived from multiple binary logistic regression models with sex, age group, BMI, highest level of education, marital status, country of birth, location and SEIFA decile entered simultaneously as predictors.

Socioeconomic status (SEIFA) data for knee arthritis and osteoarthritis are presented in the Additional file 1 (Table A2).

obese reported more stiffness (adjusted mean 40.6, 95\%CI 34.6-46.7) than those in the underweight/normal weight group (adjusted mean 25.6, 95\%CI 17.2-34.0). Participants who were obese also had worse function (adjusted mean $35.9,95 \% \mathrm{CI} 30.2-41.6$ ), compared to those classified as underweight/normal weight (adjusted mean 20.7, 95\%CI 12.7-28.7). Participants in the obese group had, on average, greater disease severity (median 6.1, IQR 0.0-23.7; Kruskal-Wallis chi-square $=8.6, \mathrm{p}=0.01$ ).

Among participants with knee OA, those classified as obese had higher pain (adjusted mean 40.1, 95\%CI 33.047.1) than participants who were overweight (adjusted mean 24.0, 95\%CI 14.6-33.4). Participants who were obese also had greater stiffness $(\mathrm{F}=5.48, \mathrm{p}=0.01)$ and worse physical function $(\mathrm{F}=6.39, \mathrm{p}<0.01)$, compared to both the overweight and underweight/normal weight groups. Obesity was also associated with increased disease severity (Kruskal-Wallis chi-square $=10.2, \mathrm{p}=0.01$ ).

\section{Discussion}

Using a national, population health approach, this research is the first to explore the relationship between obesity and the burden of hip and knee joint disease in Australia. This study has shown that overweight was associated with greater likelihood of having knee arthritis and knee OA, and that obesity was associated with 
Table 4 Impact of overweight and obesity

\begin{tabular}{|c|c|c|c|c|c|c|c|}
\hline Outcome & $n$ & Underweight or normal weight & $n$ & Overweight & $n$ & Obese & $p$ \\
\hline \multicolumn{8}{|l|}{ Hip arthritis } \\
\hline WOMAC pain & 28 & $23.1(13.8-32.4)$ & 18 & $40.8(29.4-52.2)$ & 25 & $44.3(34.3-54.4)$ & 0.01 \\
\hline WOMAC stiffness & 28 & $31.7(22.3-41.1)$ & 18 & $43.9(32.3-55.5)$ & 26 & $50.4(40.4-60.3)$ & 0.03 \\
\hline WOMAC function & 27 & $23.8(14.1-33.4)$ & 18 & $43.8(32.1-55.5)$ & 25 & $45.5(35.2-55.7)$ & 0.01 \\
\hline AQoL & 28 & $0.66(0.55-0.77)$ & 18 & $0.48(0.34-0.62)$ & 25 & $0.43(0.31-0.55)$ & 0.02 \\
\hline MAPT & 26 & $0.0(0.0-7.5)$ & 18 & $8.1(0.0-38.6)$ & 25 & $14.1(2.3-55.7)$ & 0.01 \\
\hline \multicolumn{8}{|l|}{ Hip osteoarthritis } \\
\hline WOMAC pain & 18 & $24.2(11.9-36.5)$ & 14 & $34.0(19.8-48.2)$ & 15 & $50.4(36.6-64.2)$ & 0.03 \\
\hline WOMAC stiffness & 18 & $34.7(23.4-46.1)$ & 14 & $41.6(28.5-54.6)$ & 16 & $53.5(41.2-65.8)$ & 0.09 \\
\hline WOMAC function & 18 & $27.7(15.4-40.0)$ & 14 & $39.2(25.0-53.4)$ & 15 & $52.7(38.9-66.6)$ & 0.03 \\
\hline AQoL & 18 & $0.60(0.47-0.73)$ & 14 & $0.56(0.41-0.71)$ & 15 & $0.32(0.18-0.47)$ & 0.02 \\
\hline MAPT & 16 & $2.2(0.0-17.4)$ & 14 & $3.8(1.9-27.8)$ & 15 & $39.7(9.6-58.6)$ & 0.01 \\
\hline \multicolumn{8}{|l|}{ Knee arthritis } \\
\hline WOMAC pain & 34 & $24.2(16.1-32.3)$ & 48 & $25.9(19.1-32.6)$ & 65 & $34.0(28.2-39.8)$ & 0.09 \\
\hline WOMAC stiffness & 34 & $25.6(17.2-34.0)$ & 49 & $30.1(23.1-37.0)$ & 66 & $40.6(34.6-46.7)$ & 0.01 \\
\hline WOMAC function & 33 & $20.7(12.7-28.7)$ & 48 & $26.6(20.0-33.2)$ & 65 & $35.9(30.2-41.6)$ & 0.01 \\
\hline AQoL & 35 & $0.68(0.59-0.77)$ & 49 & $0.64(0.57-0.72)$ & 65 & $0.59(0.52-0.65)$ & 0.24 \\
\hline MAPT & 34 & $0.0(0.0-5.3)$ & 44 & $0.0(0.0-9.4)$ & 58 & $6.1(0.0-23.7)$ & 0.01 \\
\hline \multicolumn{8}{|l|}{ Knee osteoarthritis } \\
\hline WOMAC pain & 15 & $23.4(10.9-35.8)$ & 26 & $24.0(14.6-33.4)$ & 47 & $40.1(33.0-47.1)$ & 0.01 \\
\hline WOMAC stiffness & 15 & $24.0(11.3-36.6)$ & 27 & $29.2(19.8-38.5)$ & 48 & $44.3(37.3-51.4)$ & 0.01 \\
\hline WOMAC function & 14 & $20.1(7.6-32.6)$ & 27 & $24.0(15.1-33.0)$ & 47 & $40.6(33.7-47.4)$ & $<0.01$ \\
\hline AQoL & 15 & $0.65(0.52-0.79)$ & 27 & $0.63(0.53-0.73)$ & 46 & $0.53(0.46-0.61)$ & 0.20 \\
\hline MAPT & 15 & $2.5(0.0-6.6)$ & 26 & $2.5(0.0-7.2)$ & 43 & $12.9(0.0-39.9)$ & 0.01 \\
\hline
\end{tabular}

WOMAC and AQoL data presented as adjusted mean $(95 \% \mathrm{Cl})$; $\mathrm{p}$-values from ANCOVA with adjustment for age and sex. MAPT data presented as median (interquartile range); $p$-values from Kruskal-Wallis test.

Higher WOMAC score indicates higher pain, greater stiffness or worse function; higher MAPT score indicates greater disease severity; lower AQoL score indicates lower HRQoL.

the highest odds of hip arthritis, knee arthritis and knee OA. Regardless of diagnosis, obesity was consistently associated with reduced physical function and greater disease severity, and people with hip arthritis or hip OA who were obese also experienced very low HRQoL, compared with population norms. Generating data on both odds of joint disease and the personal impact of concurrent obesity and joint disease (in terms of pain, function, HRQoL and disease severity), this study provides new information which is relevant for clinicians, health planners and policy makers. Our use of a population-based sampling frame is a key strength which should improve generalisability of the findings across the disease severity spectrum, in comparison to clinically-based studies which typically involve people with more severe joint disease who are already receiving care. As in many developed countries, obesity poses a significant public health problem for Australia, with recent data indicating that $68 \%$ and $55 \%$ of men and women, respectively, are overweight or obese [46].
Arthritis (including OA) and obesity have both been designated as National Health Priority Areas in Australia [47], reflecting their current and anticipated burden to the community. Reducing the burden of concurrent obesity and joint disease will undoubtedly require a multi-faceted approach which incorporates primary and secondary prevention programs, improved public education about weight loss, physical activity and joint protection, and appropriate support for clinicians to provide effective education and evidence-based care.

While comparisons across prevalence studies are difficult due to variation in case definitions (e.g. 'symptomatic,'radiographic' and 'doctor-diagnosed' arthritis or OA), our findings are in line with studies from the US, the Netherlands, England and Norway which have consistently demonstrated that obesity is associated with an increased risk of knee OA $[7,10,12,48,49]$. The association between obesity and prevalence of hip OA is less clear [6]; some studies have identified a greater risk with increased BMI (AOR 
1.72, 95\%CI 1.08-2.74 [49]) while others found no link (AOR 1.0, 95\%CI 0.7-1.5 [10] and 1.11, 95\%CI 0.41-2.97 [11]). We did not find a significant association between obesity and odds of hip OA (AOR 1.62, 95\%CI 0.77-3.45), but these analyses were based on a relatively small sample with limited power. We observed that obesity was associated with increased odds of hip arthritis, although this was considerably lower than for knee arthritis or knee OA (AOR 2.18 vs 5.47 and 7.35, respectively). It has been suggested that excessive weight may exert a greater impact on the knee joint through biomechanical factors, to which the more stable hip joint might be less susceptible [50].

Although the specific pattern of impairment varied somewhat according to diagnosis, this study provides new evidence of the association between obesity and burden of arthritis and OA. Among those with arthritis or OA, obese individuals reported more pain (for hip arthritis, hip OA and knee OA), greater stiffness (for hip arthritis, knee arthritis and knee OA), worse function (for all diagnoses), lower HRQoL (for hip arthritis and hip OA) and greater disease severity (for all diagnoses). To date, population-based research into the personal impact of obesity and hip or knee OA has been limited. Most studies have involved patients in clinical settings [17,21-24,51], including those with end-stage OA awaiting hip replacement [52]. However, the observed relationships between poorer function and obesity are consistent with previous studies that have reported reduced physical function [22,52,53], lower physical activity [17] and greater disability [24,27,28] with increasing BMI. Further research is needed to investigate specific mechanisms for reduced function and identify potential avenues for rehabilitation. An important finding was that although HRQoL was lower than Australian norms across each diagnosis group [39], obese individuals with hip arthritis or hip OA clearly had very poor HRQoL. This highlights the substantial personal impact of concurrent obesity and hip joint disease. Lower quality of life was also evident in a large study of primary care patients with hip or knee OA who were overweight or obese [17], but separate hip and knee analyses were not reported. We did not find an association between obesity and HRQoL in knee arthritis or knee OA, similar to a population-based study of Japanese women [54]. Some clinical studies have looked at associations between obesity and indicators of disease severity (e.g. WOMAC) [22,23], and our use of the MAPT instrument provides further insight into this relationship. In view of rising obesity rates, the observed relationship between obesity and disease severity may have potential implications for health services demand. However, our analyses indicate substantial within-group variability and further investigation should involve larger samples.

While an individual's understanding of their arthritis type may be limited, our methods were similar to other population-based studies (including the Australian National Health Survey) which have asked participants specifically about 'osteoarthritis' $[11,55]$. As OA is the most common form of arthritis [56], our use of the terms 'arthritis' and 'osteoarthritis' in the screening questions should have captured the majority of hip and knee OA cases. However, we acknowledge that self-reported data can be inaccurate. Our analyses may also underestimate the prevalence of doctordiagnosed arthritis and OA, given the additional participants who reported positive X-rays but did not report having been told they had arthritis or OA. We excluded this group from our analyses, in line with previous recommendations [57].

A major strength of our study was the use of federal electoral rolls to sample the Australian adult population; however, the main limitation is the low response rate (23\%). Australian government-funded population health surveys commonly use Computer Assisted Telephone Interviews or face-to-face interviews and have reported participation rates of approximately $65 \%$ [13,14]. It is possible that people are more likely to participate in government-branded research [58] and there may be a greater community awareness of these ongoing surveys. Comparing response rates between population-based studies of joint disease is difficult, due to differences in recruitment scope (e.g. local, regional or national sampling), differences in the way potential participants are approached (e.g. with a preliminary telephone call or introductory letter) and possible cultural differences between settings which could affect research participation. We found that younger individuals were less likely to participate, similar to a population-based study of knee, hip and hand OA in Norway which also found that younger individuals were less likely to respond to mailed questionnaires [49]. Although differential response rates according to age could potentially introduce bias, we do not expect this to have impacted significantly on our results given that our data show the prevalence of joint disease to be low among younger people. Additionally, we included age as a predictor in our regression models and as a covariate in the ANCOVA analyses. Despite the response rate, the sample can be considered broadly representative of the Australian population across several key characteristics. BMI distribution was similar to that reported by the Australian Bureau of Statistics (39\% underweight/normal weight, $37 \%$ overweight and $24 \%$ obese [46]. Sixty-seven per cent of the sample lived in a metropolitan area, compared with 58\% from overall Australian electoral roll data [59]. Although the study sample comprised a greater proportion of people from higher SES areas $(21 \%$ and $17 \%$ living in the ninth and tenth SEIFA deciles, respectively), higher education status closely reflected Australian government data on educational attainment [60]. In a 2011 report, 62\% of Australians aged 
35-64 years had a non-school qualification (eg technical education or university), which is comparable to that reported by our sample (61\% when limited to those aged less than 65 years). Additionally, average HRQoL for the overall sample was similar to Australian population norms (mean (SD) AQoL score for sample 0.81 (0.21) versus population norm $0.83(0.20)$ [39]).

We also acknowledge that self-reported height and weight information may underestimate true BMI [15,61] and that our cross-sectional design precludes causal inferences. It is therefore unknown, for example, whether obesity led to reduced physical function or if lower function due to OA resulted in weight gain. Finally, although we included some covariates (age and gender) in the HRQoL analyses, it is possible that the relationship between BMI and HRQoL may be affected by other factors, such as mood or depression, although we did not collect this information. This study has a number of strengths including the use of population-based sampling to include people with a range of joint disease severity, recruitment across all 8 Australian states and territories to maximise generalisability, and the evaluation of both prevalence and personal impact (across a range of constructs relevant to people with joint disease including pain, function, HRQoL and disease severity). It has generated the first national data on the obesity-related burden of hip and knee joint disease in Australia, and provides new evidence from outside the US on the relationships between obesity and key indicators of wellbeing relevant to people with hip and knee joint disease.

\section{Conclusions}

This national study has shown that obesity was associated with an increased burden of hip and knee joint disease, as evidenced by higher prevalence and greater impairment in key indicators of wellbeing. In particular, people with hip arthritis or hip OA who were obese had extremely low HRQoL. While relationships between obesity, pain, function and HRQoL are likely to be complex, these data highlight the need for public health interventions that consider overweight and obesity as both primary and secondary intervention targets for people with hip or knee joint disease.

\section{Additional file}

Additional file 1: This file presents data on the prevalence and odds of arthritis and osteoarthritis according to socioeconomic status, as referred to in the legends of Table 2 and Table 3.

\section{Abbreviations}

ANCOVA: Analysis of covariance; AOR: Adjusted odds ratio;

AQoL: Assessment of Quality of Life instrument; BMI: Body Mass Index; HRQoL: Health-Related Quality of Life; MAPT: Multi-Attribute Prioritisation Tool; OA: Osteoarthritis; OR: Odds ratio; SEIFA: Australian Socio-Economic Indexes for Areas; WOMAC: Western Ontario and McMaster Universities Osteoarthritis Index.

\section{Competing interests}

The authors declare that they have no competing interests.

\section{Authors' contributions}

Both authors contributed to the design of the study. Data collection and statistical analysis was undertaken by INA. Both authors contributed to drafting the manuscript and have approved the final manuscript.

\section{Acknowledgments}

The authors wish to thank Professor lan Wicks and the study participants for their support of this research. We also wish to thank Dr Lucy Busija for statistical advice and constructive feedback on the manuscript, Mark Tacey for statistical advice and Wendy Lemaire for assistance with data entry. This research was supported in part by a Physiotherapy Research Foundation and United Pacific Industries Thermoskin Research Grant (\#T09-THE003). Dr Ackerman was supported by a National Health and Medical Research Council of Australia Public Health (Australian) Early Career Fellowship (\#520004). Professor Osborne was supported in part by a National Health and Medical Research Council of Australia Population Health Career Development Award (\#400391). The funding bodies had no role in the study design; in the collection, analysis, and interpretation of data; in the writing of the manuscript; or in the decision to submit the manuscript for publication.

\section{Author details}

${ }^{1}$ Melbourne EpiCentre, Department of Medicine (Royal Melbourne Hospital), The University of Melbourne, Melbourne, Australia. ${ }^{2}$ Public Health Innovation, Population Health Strategic Research Centre, Deakin University, Melbourne, Australia.

Received: 5 March 2012 Accepted: 17 December 2012 Published: 20 December 2012

\section{References}

1. Australian Orthopaedic Association National Joint Replacement Registry: Annual report. Adelaide: Australian Orthopaedic Association; 2011.

2. Sassi F, Devaux M, Cecchini M, Rusticelli E: The obesity epidemic: Analysis of past and projected future trends in selected OECD countries. Paris: OECD Publishing; 2009

3. Australian Institute of Health and Welfare: Australia's health 2010. Canberra: Australian Institute of Health and Welfare; 2010.

4. Anandacoomarasamy A, Fransen M, March L: Obesity and the musculoskeletal system. Curr Opin Rheumatol 2009, 21:71-77.

5. Sowers MR, Karvonen-Gutierrez CA: The evolving role of obesity in knee osteoarthritis. Curr Opin Rheumatol 2010, 22:533-537.

6. Lievense A, Bierma-Zeinstra S, Verhagen AP, van Baar ME, Verhaar JAN, Koes BW: Influence of obesity on the development of osteoarthritis of the hip: A systematic review. Rheumatology 2002, 41:1155-1162.

7. Felson DT, Anderson JJ, Naimark A, Walker AM, Meenan RF: Obesity and knee osteoarthritis, The Framingham Study. Ann Intern Med 1988, 109:18-24.

8. Hart DJ, Doyle DV, Spector TD: Incidence and risk factors for radiographic knee osteoarthritis in middle-aged women: The Chingford Study. Arthritis Rheum 1999, 42:17-24.

9. Gelber AC, Hochberg MC, Mead LA, Wang NY, Wigley FM, Klag MJ: Body mass index in young men and the risk of subsequent knee and hip osteoarthritis. Am J Med 1999, 107:542-548.

10. Reijman M, Pols HAP, Bergink AP, Hazes JMW, Belo JN, Lievense AM, BiermaZeinstra SMA: Body mass index associated with onset and progression of osteoarthritis of the knee but not of the hip: The Rotterdam Study. Ann Rheum Dis 2007, 66:158-162.

11. Grotle M, Hagen K, Natvig B, Dahl F, Kvien T: Obesity and osteoarthritis in knee, hip and/or hand: An epidemiological study in the general population with 10 years follow-up. BMC Musculoskelet Disord 2008, 9:132.

12. Murphy L, Schwartz TA, Helmick CG, Renner JB, Tudor G, Koch G, Dragomir A, Kalsbeek WD, Luta G, Jordan JM: Lifetime risk of symptomatic knee osteoarthritis. Arthritis Care Res 2008, 59:1207-1213.

13. Busija L, Hollingsworth B, Buchbinder R, Osborne RH: Role of age, sex, and obesity in the higher prevalence of arthritis among lower socioeconomic groups: A population-based survey. Arthritis Care Res 2007, 57:553-561. 
14. Busija L, Buchbinder R, Osborne RH: Quantifying the impact of transient joint symptoms, chronic joint symptoms, and arthritis: A populationbased approach. Arthritis Rheum 2009, 61:1312-1321.

15. Australian Bureau of Statistics: National Health Survey: Summary of Results, 2007-2008 (Reissue).2012. http://www.abs.gov.au/AUSSTATS/abs@.nsf/ Latestproducts/4364.0Main\%20Features12007-2008\%20(Reissue)? opendocument $\&$ tabname $=$ Summary $\&$ prodno $=4364.0 \&$ issue $=2007-2008 \% 20$ (Reissue)\&num=\&view=.

16. Gill T, Hill C, Adams R, Broderick D, Black J, Taylor A: I know I have arthritis but I don't know what type. Understanding and knowledge of this chronic condition. BMC Musculoskelet Disord 2010, 11:174.

17. Rosemann T, Grol R, Herman K, Wensing M, Szecsenyi J: Association between obesity, quality of life, physical activity and health service utilization in primary care patients with osteoarthritis. Int J Behav Nutr Phys Act 2008, 5:4

18. Losina E, Walensky RP, Reichmann WM, Holt HL, Gerlovin H, Solomon DH, Jordan JM, Hunter DJ, Suter LG, Weinstein AM, et al: Impact of obesity and knee osteoarthritis on morbidity and mortality in older Americans. Ann Intern Med 2011, 154:217-226.

19. Anandacoomarasamy A, Caterson ID, Leibman S, Smith GS, Sambrook PN, Fransen M, March LM: Influence of BMI on Health-related Quality of Life: Comparison between an obese adult cohort and age-matched population norms. Obesity 2009, 17:2114-2118.

20. Marks R: Obesity profiles with knee osteoarthritis: Correlation with pain, disability, disease progression. Obesity 2007, 15:1867-1874.

21. Perrot S, Poiraudeau S, Kabir-Ahmadi M, Rannou F: Correlates of pain intensity in men and women with hip and knee osteoarthritis. Results of a national survey: The French ARTHRIX study. Clin J Pain 2009, 25:767-772.

22. Elbaz A, Debbi EM, Segal G, Haim A, Halperin N, Agar G, Mor A, Debi R: Sex and Body Mass Index correlate With Western Ontario and McMaster Universities Osteoarthritis Index and quality of life scores in knee osteoarthritis. Arch Phys Med Rehabil 2011, 92:1618-1623.

23. Creamer $P$, Lethbridge-Cejku M, Hochberg MC: Factors associated with functional impairment in symptomatic knee osteoarthritis. Rheumatology 2000, 39:490-496.

24. Ambrose NL, Keogan F, O'Callaghan JP, O'Connell PG: Obesity and disability in the symptomatic Irish knee osteoarthritis population. Ir J Med Sci 2010, 179:265-268.

25. Verbrugge LM, Gates DM, Ike RW: Risk factors for disability among U.S. adults with arthritis. J Clin Epidemiol 1991, 44:167-182.

26. Ettinger WH, Davis MA, Neuhaus JM, Mallon KP: Long-term physical functioning in persons with knee osteoarthritis from NHANES I: Effects of comorbid medical conditions. J Clin Epidemiol 1994, 47:809-815.

27. Jordan JM, Luta G, Renner JB, Linder GF, Dragomir A, Hochberg MC, Fryer JG: Self-reported functional status in osteoarthritis of the knee in a rural southern community: The role of sociodemographic factors, obesity, and knee pain. Arthritis Care Res 1996, 9:273-278.

28. Okoro CA, Hootman JM, Strine TW, Balluz LS, Mokdad AH: Disability, arthritis, and body weight among adults 45 years and older. Obes Res 2004, 12:854-861.

29. Cheng YJ, Hootman JM, Murphy LB, Langmaid GA, Helmick CG: Prevalence of doctor-diagnosed arthritis and arthritis-attributable activity limitation United States, 2007-2009. MMWR Morb Mortal Wkly Rep 2010, 59:1261-1265.

30. Allen KD, Helmick CG, Schwartz TA, DeVellis RF, Renner JB, Jordan JM: Racial differences in self-reported pain and function among individuals with radiographic hip and knee osteoarthritis: The Johnston County Osteoarthritis Project. Osteoarthr Cartil 2009, 17:1132-1136.

31. Allen KD, Chen J-C, Callahan LF, Golightly YM, Helmick CG, Renner JB, Schwartz TA, Jordan JM: Racial differences in knee osteoarthritis pain: Potential contribution of occupational and household tasks. J Rheumatol 2012, 39:337-344

32. Lawrence RC, Felson DT, Helmick CG, Arnold LM, Choi H, Deyo RA, Gabriel $S$, Hirsch R, Hochberg MC, Hunder GG, et al: Estimates of the prevalence of arthritis and other rheumatic conditions in the United States: Part II. Arthritis Rheum 2008, 58:26-35.

33. Helmick CG, Felson DT, Lawrence RC, Gabriel S, Hirsch R, Kwoh CK, Liang $\mathrm{MH}$, Kremers HM, Mayes MD, Merkel PA, et al: Estimates of the prevalence of arthritis and other rheumatic conditions in the United States: Part I. Arthritis Rheum 2008, 58:15-25.

34. Bellamy N: WOMAC Osteoarthritis Index. Brisbane: Australia: User guide IX; 2009.
35. McConnell S, Kolopack P, Davis AM: The Western Ontario and McMaster Universities Osteoarthritis Index (WOMAC): A review of its utility and measurement properties. Arthritis Care Res 2001, 45:453-461.

36. Collins NJ, Misra D, Felson DT, Crossley KM, Roos EM: Measures of knee function: International Knee Documentation Committee (IKDC) Subjective Knee Evaluation Form, Knee Injury and Osteoarthritis Outcome Score (KOOS), Knee Injury and Osteoarthritis Outcome Score Physical Function Short Form (KOOS-PS), Knee Outcome Survey Activities of Daily Living Scale (KOS-ADL), Lysholm Knee Scoring Scale, Oxford Knee Score (OKS), Western Ontario and McMaster Universities Osteoarthritis Index (WOMAC), Activity Rating Scale (ARS), and Tegner Activity Score (TAS). Arthritis Care Res 2011, 63:S208-S228.

37. Hawker GA, Wright JG, Coyte PC, Williams JI, Harvey B, Glazier R, Badley EM: Differences between men and women in the rate of use of hip and knee arthroplasty. N Engl J Med 2000, 342:1016-1022.

38. Hawthorne G, Richardson J, Osborne R: The Assessment of Quality of Life (AQoL) instrument: A psychometric measure of Health-Related Quality of Life. Qual Life Res 1999, 8:209-224.

39. Hawthorne G, Osborne R: Population norms and meaningful differences for the Assessment of Quality of Life (AQoL) measure. Aust N Z J Public Health 2005, 29:136-142.

40. Busija L, Pausenberger E, Haines TP, Haymes S, Buchbinder R, Osborne RH: Adult measures of general health and Health-Related Quality of Life. Arthritis Care Res 2011, 63:S383-S412.

41. Ackerman IN, Graves SE, Wicks IP, Bennell KL, Osborne RH: Severely compromised quality of life in women and those of lower socioeconomic status waiting for joint replacement surgery. Arthritis Care Res 2005, 53:653-658.

42. Osborne R, Haynes K, Jones C, Chubb P, Robbins D, Graves S: Orthopaedic Waiting List Project Summary Report. Melbourne: Victorian Government Department of Human Services; 2006.

43. World Health Organization: Obesity: Preventing and managing the global epidemic. Geneva: World Health Organization; 2000.

44. Australian Electoral Commission: Current federal electoral divisions. 2012 http://www.aec.gov.au/profiles/

45. Australian Bureau of Statistics: 2033.0.55.001 - Census of Population and Housing: Socio-Economic Indexes for Areas (SEIFA), Australia - Data only, 2006. 2012. http://www.abs.gov.au/AUSSTATS/abs@.nsf/Lookup/2033.0.55.001Main +Features12006? OpenDocument.

46. Australian Bureau of Statistics: 2007-2008: Overweight and obesity in adults in Australia: A snapshot. 2012. http://www.ausstats.abs.gov.au/ausstats/ subscriber.nsf/0/7DC7186F4A9950DECA25789C0023DCEF/\$File/ 4842055001_200708.pdf.

47. Australian Institute of Health and Welfare: Health priority areas. 2012. http://www.aihw.gov.au/health-priority-areas/.

48. Coggon D, Reading I, Croft P, McLaren M, Barrett D, Cooper C: Knee osteoarthritis and obesity. Int J Obes Relat Metab Disord 2001, 25:622-627.

49. Grotle M, Hagen K, Natvig B, Dahl F, Kvien T: Prevalence and burden of osteoarthritis: Results from a population survey in Norway. $J$ Rheumatol 2008, 35:677-684.

50. Sharma L, Chang A: Overweight: Advancing our understanding of its impact on the knee and the hip. Ann Rheum Dis 2007, 66:141-142.

51. Creamer $P$, Lethbridge-Cejku M, Hochberg M: Determinants of pain severity in knee osteoarthritis: Effect of demographic and psychosocial variables using 3 pain measures. J Rheumatol 1999, 26:1785-1792.

52. Lübbeke A, Duc S, Garavaglia G, Finckh A, Hoffmeyer P: BMI and severity of clinical and radiographic signs of hip osteoarthritis. Obesity 2009, 17:1414-1419.

53. Sharma L, Cahue S, Song J, Hayes K, Pai Y-C, Dunlop D: Physical functioning over three years in knee osteoarthritis: Role of psychosocial, local mechanical, and neuromuscular factors. Arthritis Rheum 2003, 48:3359-3370

54. Norimatsu T, Osaki M, Tomita M, Ye Z, Abe Y, Honda S, Kanagae M, Mizukami S, Takamura N, Kusano Y, et al: Factors predicting health-related quality of life in knee osteoarthritis among community-dwelling women in Japan: The Hizen-Oshima study. Orthopedics 2011, 34:e535-e540.

55. Australian Bureau of Statistics: 2007-2008 National Health Survey Users' Guide - Electronic. 2012. http://www.ausstats.abs.gov.au/ausstats/subscriber.nsf/0/ CCOFB5A08570984ECA25762E0017CF2B/\$File/4363055001_2007-08.pdf.

56. Zhang W, Moskowitz RW, Nuki G, Abramson S, Altman RD, Arden N, BiermaZeinstra S, Brandt KD, Croft P, Doherty M, et al: OARSI recommendations 
for the management of hip and knee osteoarthritis, Part II: OARSI evidence-based, expert consensus guidelines. Osteoarthr Cartil 2008, 16:137-162.

57. Bolen J, Helmick CG, Sacks JJ, Gizlice Z, Potter C: Should people who have joint symptoms, but no diagnosis of arthritis from a doctor, be included in surveillance efforts? Arthritis Care Res 2011, 63:150-154.

58. Dillman DA: Mail and internet surveys. The tailored design method ( ${ }^{\text {nd }}$ ed.). Hoboken: John Wiley \& Sons; 2007.

59. Australian Electoral Commission: Demographic classification of divisions. 2012 http://results.aec.gov.au/13745/Website/GeneralDemographicByDivision13745-NAT.htm

60. Australian Bureau of Statistics: 6227.0 - Education and work, Australia, May 2011. 2012. http://www.abs.gov.au/ausstats/abs@.nsf/mf/6227.0.

61. Flegal KM, Carroll MD, Ogden CL, Johnson CL: Prevalence and trends in obesity among US adults, 1999-2000. JAMA 2002, 288:1723-1727.

doi:10.1186/1471-2474-13-254

Cite this article as: Ackerman and Osborne: Obesity and increased burden of hip and knee joint disease in Australia: Results from a national survey. BMC Musculoskeletal Disorders 2012 13:254.

\section{Submit your next manuscript to BioMed Central and take full advantage of:}

- Convenient online submission

- Thorough peer review

- No space constraints or color figure charges

- Immediate publication on acceptance

- Inclusion in PubMed, CAS, Scopus and Google Scholar

- Research which is freely available for redistribution 